\title{
Thyroid function and non-alcoholic fatty liver disease in hyperthyroidism patients
}

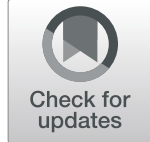

\author{
Bairong Wang ${ }^{1,2 \dagger}$, Baomin Wang ${ }^{1 \dagger}$, Yumei Yang ${ }^{1}$, Jing Xu', Mengyang Hong ${ }^{1}$, Mingfeng Xia ${ }^{1}$, Xiaomu Li ${ }^{1 *}$ (D) and
} Xin Gao'

\begin{abstract}
Background: Although thyroid function has been demonstrated to be associated with non-alcoholic fatty liver disease (NAFLD) in different population, the prevalence and features of NAFLD in hyperthyroidism have not been reported. The present study aims to investigate the prevalence of NAFLD and association of thyroid function and NAFLD in hyperthyroidism patients.
\end{abstract}

Methods: This cross-sectional study was performed in Zhongshan Hospital, Fudan University, China. A total 117 patients with hyperthyroidism were consecutively recruited from 2014 to 2015. Thyroid function and other clinical features were measured, liver fat content was measured by color Doppler ultrasonically, NAFLD was defined in patients with liver fat content more than 9.15\%. Statistical analyses were performed with SPSS software package version 13.0.

Results: The prevalence of NAFLD was $11.97 \%$ in hyperthyroidism. Patient with NAFLD had lower free triiodothyronine (FT3) and free thyroxine (FT4) levels than patients without NAFLD $(P<0.05)$. After adjusting for age, gender, metabolic parameters and inflammation factors, higher FT3 were associated with lower liver fat content $(\beta=-0.072, P=0.009)$ and decreased odds ratio of NAFLD $(\mathrm{OR}=0.267,95 \% \mathrm{Cl} 0.087-0.817, P=0.021)$.

Conclusions: FT3 level was negatively associated with the liver fat content in this population. These results may provide new evidence in the role of thyroid hormone on the regulation of liver fat content and NAFLD.

Keywords: Thyroid function, Non-alcoholic fatty liver disease, Hyperthyroidism

\section{Background}

Obesity and metabolic disease are becoming global issues, and the prevalence of Nonalcoholic fatty liver disease (NAFLD) is up to $20-30 \%$ [1-3]. NAFLD is a broad spectrum of diseases involves non-alcoholic simple fatty liver (NASFL), nonalcoholic steatohepatitis (NASH), liver cirrhosis, and hepatocellular carcinoma. NAFLD is becoming the main cause of cirrhosis, and NAFLD has been one of the major cause of the hepatocellular carcinoma [4]. Pathogenesis of NAFLD is not yet fully understood,

\footnotetext{
* Correspondence: li.xiaomu@zs-hospital.sh.cn

${ }^{\dagger}$ Bairong Wang and Baomin Wang contributed equally to this work.

${ }^{1}$ Present address: The Department of Endocrinology, Zhongshan hospital,

Fudan University, NO. 180 Fenglin Road, Shanghai 200032, China

Full list of author information is available at the end of the article
}

it's widely accepted that NAFLD is caused by the interaction of complex genetic background and environment factors [5], insulin resistance enhances the lipolysis of adipose tissue, impact a mass of free fatty acids (FFA) into the liver, leading to the deposition of FFA and triglycerides in the liver [6].

The thyroid hormone plays an important role in glucose metabolism, lipid metabolism, and insulin resistance [7, 8]. Emerging evidences have indicated the relationship between thyroid hormone concentration and NAFLD. Rochon et al. firstly reported the association between hypothyroidism and insulin resistance in 2003 [9]. Several other studies demonstrated that morbidity of NAFLD has an inverse association with thyroid hormone levels in the

(c) The Author(s). 2021 Open Access This article is licensed under a Creative Commons Attribution 4.0 International License, which permits use, sharing, adaptation, distribution and reproduction in any medium or format, as long as you give appropriate credit to the original author(s) and the source, provide a link to the Creative Commons licence, and indicate if changes were made. The images or other third party material in this article are included in the article's Creative Commons licence, unless indicated otherwise in a credit line to the material. If material is not included in the article's Creative Commons licence and your intended use is not permitted by statutory regulation or exceeds the permitted use, you will need to obtain permission directly from the copyright holder. To view a copy of this licence, visit http://creativecommons.org/licenses/by/4.0/ The Creative Commons Public Domain Dedication waiver (http://creativecommons.org/publicdomain/zero/1.0/) applies to the data made available in this article, unless otherwise stated in a credit line to the data. 
hypothyroid or euthyroid populations [10, 11]. Thyroid hormone analogues [11] and thyroid receptor beta antagonist [12] have been used to reduce liver fat content in animal models. Clinical studies also demonstrated that thyroid hormone analogues may improve NAFLD [13, 14]. However, there are no studies on the prevalence of NAFLD in hyperthyroid patients, and little is known about the association of thyroid hormone and liver fat content under hyperthyroidism condition. It should considered that the insulin resistance and oxidant stress [15] have been reported in patients with hyperthyroidism, both of which were related to the pathology of NAFLD. Therefore, it is necessary to explore liver fat content, NAFLD and possible mechanism in patients with hyperthyroidism.

The aim of the present study is to determine the association between thyroid hormone levels, and liver fat content in patients with hyperthyroidism and investigate the differences of clinical characteristics, including thyroid hormone levels, between patients with or without NAFLD. This study were conducted in 117 patients with hyperthyroidism, and liver fat content was measured by ultrasonography with our previous established methods [16].

\section{Methods}

\section{Study population}

The present study consecutively enrolled 117 patients with new-onset or recurrent hyperthyroidism from outpatient clinic in Department of Endocrinology, Zhongshan Hospital, between 2014 to 2015. The sample size was based on previous similar studies [17-19]. The Diagnose criteria of hyperthyroidism includes:1) hyper-metabolic syndrome include nervousness, irritability, increased perspiration, heart racing, hand tremors, anxiety, difficulty sleeping, thinning of the skin, fine brittle hair, muscular weakness, and other typical symptoms; 2) Laboratory tests show a low thyroid stimulating hormone (TSH), raised triiodothyronine (T3) or thyroxine (T4), and positive anti-TSH-receptor antibodies. 3) defuse increased radio-iodine uptake by the thyroid.

Exclusion criteria: 1) Patients with the history of taking medication that may affect thyroid function; 2) Hyperthyroidism crisis; 3) Hyperthyroid heart disease; 4) History of hypothalamus or pituitary disease; 5) Long-term alcohol consumption; 6) History of viral hepatitis, autoimmune hepatitis, Wilson's disease; 7) Total parenteral nutrition, inflammatory bowel disease,or Cushing's syndrome; 8) taking tamoxifen, amiodarone, sodium

Table 1 Clinical characteristics of 117 cases with hyperthyroidism

\begin{tabular}{|c|c|c|c|c|}
\hline Characteristics & $\begin{array}{l}\text { Total } \\
(n=117)\end{array}$ & $\begin{array}{l}\text { Without NAFLD } \\
(n=103)\end{array}$ & $\begin{array}{l}\text { With NAFLD } \\
(n=14)\end{array}$ & $P$-value \\
\hline Age (years) & $45.35 \pm 12.78$ & $44.72 \pm 13.04$ & $50.00 \pm 9.88$ & 0.148 \\
\hline Gender(M/F) & $34 / 83$ & $29 / 74$ & $5 / 9$ & 0.559 \\
\hline $\mathrm{BMI}\left(\mathrm{kg} / \mathrm{m}^{2}\right)$ & $22.55 \pm 3.38$ & $22.19 \pm 3.31$ & $25.23 \pm 2.72$ & 0.001 \\
\hline Waist circumference $(\mathrm{cm})$ & $80.82 \pm 9.52$ & $79.93 \pm 9.19$ & $90.29 \pm 8.06$ & 0.005 \\
\hline $\mathrm{SBP}(\mathrm{mmHg})$ & $122.52 \pm 13.79$ & $121.82 \pm 13.77$ & $127.71 \pm 13.33$ & 0.115 \\
\hline $\mathrm{DBP}(\mathrm{mmHg})$ & $74.32 \pm 9.35$ & $73.73 \pm 9.34$ & $78.71 \pm 8.50$ & 0.115 \\
\hline $\mathrm{FBG}(\mathrm{mmol} / \mathrm{L})$ & $5.09 \pm 1.08$ & $5.04 \pm 0.91$ & $5.48 \pm 1.92$ & 0.159 \\
\hline f-INS (mU/L) & $8.70(6.50,10.60)$ & $8.70(6.20,10.55)$ & $8.90(7.35,11.63)$ & 0.690 \\
\hline $\mathrm{TG}(\mathrm{mmol} / \mathrm{L})$ & $0.99 \pm 0.49$ & $0.94 \pm 0.43$ & $1.36 \pm 0.71$ & 0.048 \\
\hline $\mathrm{TC}(\mathrm{mmol} / \mathrm{L})$ & $3.45 \pm 0.81$ & $3.37 \pm 0.76$ & $4.00 \pm 0.95$ & 0.006 \\
\hline $\mathrm{LDL}(\mathrm{mmol} / \mathrm{L})$ & $1.79 \pm 0.66$ & $1.72 \pm 0.62$ & $2.26 \pm 0.76$ & 0.004 \\
\hline IL6(pg/ml) & $2.30(2.00,3.00)$ & $2.30(2.00,3.00)$ & $2.10(2.00,3.00)$ & 0.564 \\
\hline HCRP (mg/L) & $0.80(0.40,1.98)$ & $0.80(0.40,2.05)$ & $0.90(0.70,1.70)$ & 0.594 \\
\hline UA (umol/L) & $292.89 \pm 69.51$ & $293.14 \pm 66.50$ & $291.07 \pm 91.53$ & 0.917 \\
\hline $\mathrm{ALT}(\mathrm{U} / \mathrm{L})$ & $36.80 \pm 33.06$ & $38.32 \pm 34.45$ & $25.64 \pm 16.96$ & 0.179 \\
\hline AST(U/L) & $27.15 \pm 16.61$ & $27.86 \pm 17.10$ & $21.86 \pm 11.50$ & 0.206 \\
\hline $\mathrm{FT} 3(\mathrm{pmol} / \mathrm{L})$ & $20.42 \pm 12.73$ & $21.69 \pm 12.57$ & $11.09 \pm 10.01$ & 0.002 \\
\hline FT4(pmol/L) & $54.15 \pm 29.87$ & $57.11 \pm 29.58$ & $32.41 \pm 22.73$ & 0.002 \\
\hline TSH (ulU/ml) & $0.005(0.005,0.010)$ & $0.005(0.005,0.010)$ & $0.005(0.005,0.508)$ & 0.824 \\
\hline HOMA-IR & $1.90(1.38,2.54)$ & $1.86(1.37,2.52)$ & $2.26(1.56,3.22)$ & 0.956 \\
\hline
\end{tabular}

BMI Body-mass-index, SBP Systolic Blood Pressure, DBP Diastolic blood pressure, FBG Fasting blood glucose, $f$-INS Fasting insulin, TG Triglyceride, TC Serum total cholesterol, LDL Low density lipoprotein, IL-6 Interleukin-6, HCRBP Hypersensitive C-reactive protein, UA Uric acid, ALT Alanine aminotransferase, AST Aspartate aminotransferase, FT3 Free triiodothyronine, FT4 Free thyroxine, TSH Thyroid-stimulating hormone, HOMA-IR Homeostasis model assessment for insulin resistance 
valproate, methotrexate, or glucocorticoids. Written, informed consent was obtained from all of the participants, and the study was approved by the ethics committee of Zhongshan Hospital, Fudan University, China.

\section{Clinical and biochemical measurements}

The clinical data including age, gender, history of drinking and alcohol intake were obtained from the clinical documents of endocrinology clinic. According to the routine protocol, the information of complete physical examination including height, weight, waist circumference (Wc), and blood pressure were recorded after overnight fasting for $12 \mathrm{~h}$, and body mass index (BMI) was calculated by body weight $(\mathrm{kg}) /$ height squared $\left(\mathrm{m}^{2}\right)$. The general laboratory tests (Japan Hitachi 7600 biochemical analyzer) included the levels of fasting blood glucose (FBG), total cholesterol (TC), triglyceride (TG), high-density lipoprotein cholesterol (HDL-C), low-density lipoprotein cholesterol (LDL-C), alanine aminotransferase (ALT), aspartate aminotransferase (AST), uric acid (UA). Free triiodothyronine (FT3), free thyroxine (FT4), TSH, thyrotrophin receptor antibody (TRAb), fasting plasma insulin (f-INS), and hyper-sensitive C-reaction protein (HCRP) were also measured (electrochemiluminescence, Roche Diagnostics, Germany). Insulin resistance index (HOMA-IR) were calculated by FBG $\times$ fasting insulin / 22.5. All subjects received a ultrasonic examination performed with a GE Vivid7 ultrasound machine as described previously [16]. Briefly, in the sagittal liver/right kidney view of ultrasound images, a region of interest (ROI) in the liver parenchyma and the kidney cortex was selected. In the right liver intercostals view of ultrasound images, a ROI in the liver far-field region was selected. And then all images were analyzed-of by using NIHimage software to estimate the gray scale mean value of the pixels within the two ROIs and calculated the hepatic/renal echo-intensity ratio and hepatic echointensity attenuation rate. A 3D abdominal phantom Model was introduced to standardize the measured values of US $H / R$ ratio and hepatic echo- intensity attenuation rate, finally we can compute the liver fat content as the following formula: Liver fat content $(\%)=62.592 \times$ US hepatic/renal ratio $+168.076 \times$ US hepatic attenuation rate -27.863 . NAFLDwas defined

Table 2 Clinical characteristics of all cases by tertiles of free triiodothyronine

\begin{tabular}{|c|c|c|c|c|}
\hline FT3 & $\mathrm{T} 1(\leqq 12.70 \mathrm{pmol} / \mathrm{L})$ & $\mathrm{T} 2(12.71 \sim 25.80 \mathrm{pmol} / \mathrm{L})$ & $\mathrm{T} 3(>25.80 \mathrm{pmol} / \mathrm{L})$ & $P$ for trend \\
\hline Age (years) & $49.9 \pm 11.9$ & $46.1 \pm 13.8$ & $40.1 \pm 10.8 \%$ 々 & 0.002 \\
\hline Gender(M/F) & $14 / 25$ & $11 / 28$ & $9 / 30$ & 0.455 \\
\hline FT4(pmol/L) & $25.28 \pm 10.26$ & $48.41 \pm 14.11 ※$ & $88.78 \pm 17.28 ※ 乞$ & $<0.001$ \\
\hline TSH (ulU/ml) & $0.01(0.005,1.470)$ & $0.005(0.005,0.010) ※$ & $0.005(0.005,0.010) ※$ & $<0.001$ \\
\hline $\mathrm{BMI}\left(\mathrm{kg} / \mathrm{m}^{2}\right)$ & $23.41 \pm 3.30$ & $23.40 \pm 3.41$ & $20.85 \pm 2.82 ※ \bar{\tau}$ & $<0.001$ \\
\hline Waist circumference $(\mathrm{cm})$ & $83.17 \pm 8.82$ & $81.43 \pm 10.19$ & $77.79 \pm 8.95 ※$ & 0.113 \\
\hline $\mathrm{SBP}(\mathrm{mmHg})$ & $121.46 \pm 13.26$ & $124.72 \pm 10.94$ & $121.38 \pm 16.68$ & 0.480 \\
\hline $\mathrm{DBP}(\mathrm{mmHg})$ & $74.92 \pm 9.10$ & $75.79 \pm 8.54$ & $72.26 \pm 10.21$ & 0.221 \\
\hline FBG $(\mathrm{mmol} / \mathrm{L})$ & $5.01 \pm 1.30$ & $5.01 \pm 0.79$ & $5.25 \pm 1.09$ & 0.541 \\
\hline f-INS (mU/L) & $8.30(5.50,9.70)$ & $7.90(5.80,11.1)$ & $9.20(7.00,11.00)$ & 0.367 \\
\hline $\mathrm{TG}(\mathrm{mmol} / \mathrm{L})$ & $1.03 \pm 0.48$ & $1.14 \pm 0.58$ & $0.79 \pm 0.28 \%$ 元 & 0.006 \\
\hline $\mathrm{TC}(\mathrm{mmol} / \mathrm{L})$ & $3.91 \pm 0.85$ & $3.47 \pm 0.77 ※$ & $2.94 \pm 0.43 \%$ 级 & $<0.001$ \\
\hline LDL (mmol/L) & $2.23 \pm 0.63$ & $1.76 \pm 0.62 ※$ & $1.36 \pm 0.38 \%$ 论 & $<0.001$ \\
\hline IL6(pg/ml) & $2.20(2.00,3.00)$ & $2.10(2.00,2.58)$ & $2.60(2.10,3.38)$ & 0.352 \\
\hline $\mathrm{HCRP}(\mathrm{mg} / \mathrm{L})$ & $0.80(0.40,1.98)$ & $0.70(0.30,2.20)$ & $1.00(0.45,2.15)$ & 0.389 \\
\hline UA (umol/L) & $295.90 \pm 77.90$ & $282.28 \pm 56.85$ & $300.68 \pm 72.63$ & 0.486 \\
\hline $\operatorname{ALT}(U / L)$ & $24.92 \pm 19.76$ & $36.79 \pm 26.95 ※$ & $48.69 \pm 43.93 ※$ & 0.006 \\
\hline AST(U/L) & $21.46 \pm 10.29$ & $26.36 \pm 13.41$ & $33.62 \pm 21.91 ※$ & 0.004 \\
\hline Liver fat content(\%) & $6.75 \pm 3.45$ & $6.14 \pm 4.34$ & $4.01 \pm 2.43 ※$ 访 & 0.002 \\
\hline With NAFLD/without NAFLD & $10 / 29$ & $3 / 36$ & $1 / 38 ※$ & 0.004 \\
\hline HOMA-IR & $1.70(1.11,2.64)$ & $1.76(1.19,2.55)$ & $2.04(1.63,2.54)$ & 0.289 \\
\hline
\end{tabular}

※ $<0.05$ versus $\mathrm{T} 1$ group ; 2 is $P<0.05$ versus $\mathrm{T} 2$ group 

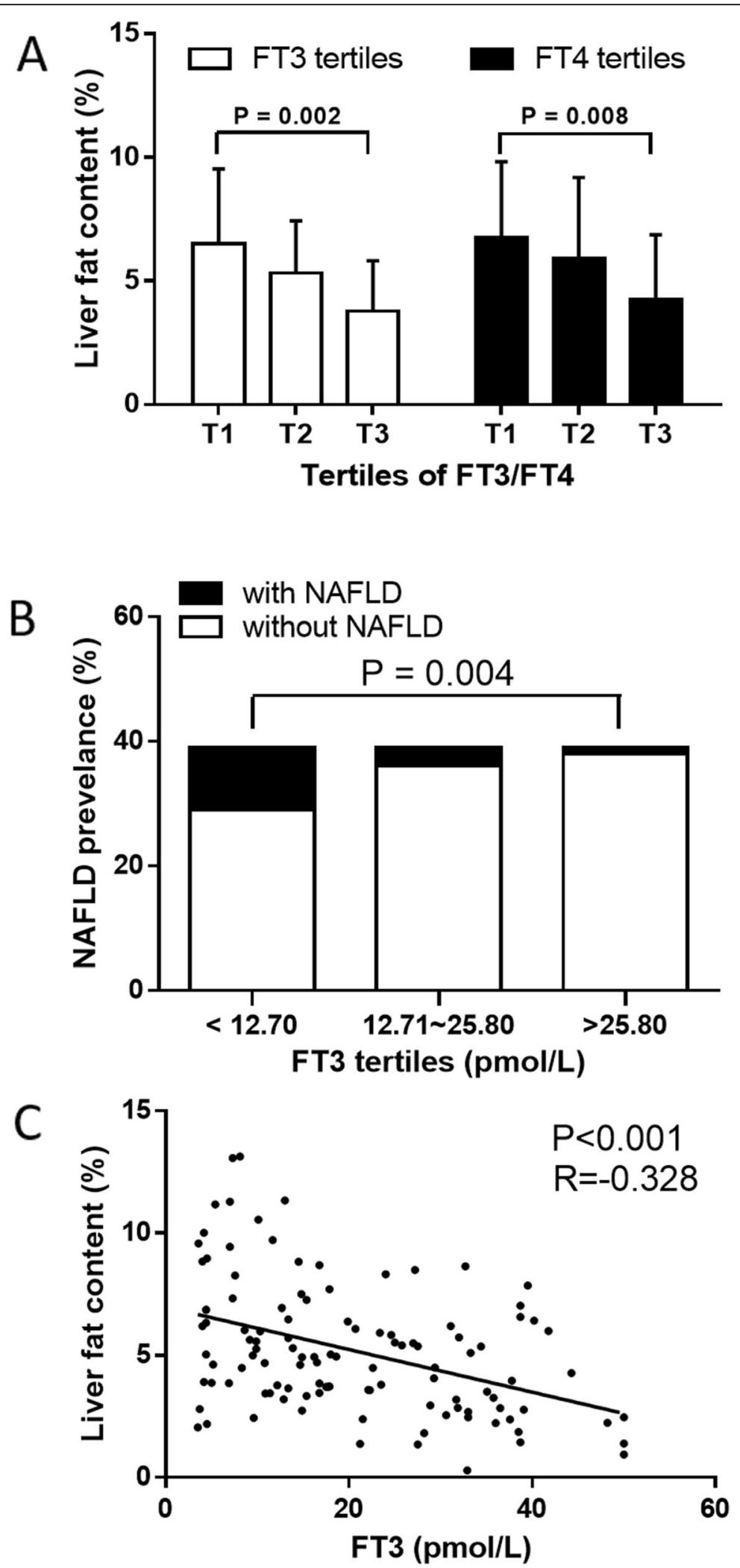

Fig. 1 (See legend on next page.) 
(See figure on previous page.)

Fig. 1 Correlation of liver fat content and prevalence of NAFLD with thyroid hormoe levels in hyperthyroidism patients. a The FT3/FT4 levels in respective tertiles was plotted against liver fat content, the liver fat content showed a decreased trend with increasing of FT3/FT4 levels; $\mathbf{b}$ The FT3 levels in respective tertiles was plotted against prevalence of NAFLD, the prevalence of NAFLD showed a decreased trend with increasing of FT3 levels; c The FT3 concentration was plotted against liver fat content, and a negative significant correlation was found between FT3 and liver fat content

in patients with liver fat content more than $9.15 \%$ according to our previous research [16]. .

\section{Statistical analyses}

Normal distribution variables were expressed as the mean \pm standard deviation; Comparisons of normal distribution variables between the two groups were performed with the independent sample $\mathrm{T}$ test; one-way ANOVA test was used in comparison among the three groups. Non-normally distributed variables were expressed as the median (inter-quartile range), comparisons of nonnormally distributed variables between the two groups were performed with the Mann-Whiteny test, while Kruskal-Wallis test was used in comparison of the three groups. The chi-squared test was used to compare the rates. The correlation between liver fat content and thyroid function and other clinical indexes was analyzed by Pearson correlation analysis. Multiple linear regression analysis was used to detect the independent correlation between thyroid function and liver fat content; statistical analyses were performed with SPSS software package version 13.0.

\section{Results}

\section{General characteristics of the study population}

The general clinical information all patients was showed in Table 1.The present study included 117 patients (34 males, 83 females), including 6 patients were subclinical hyperthyroidism. The average age was $45.35 \pm 12.78$ years, BMI was $22.55 \pm 3.38 \mathrm{~kg} / \mathrm{m}^{2}$. The prevalence of NAFLD was $11.97 \%$ in this hyperthyroidism population. Patients with NAFLD had lower FT3, FT4 levels $(p<$ $0.05)$ and higher BMI, Wc, TG, TC, LDL levels $(p<0.05$, respectively) than patients without NAFLD. There were no significant differences in age, gender, blood pressure levels, TSH, ALT, AST, UA, FBG, f-INS, IL-6, HCRP and HOMA-IR between the two groups $(p>0.05)$.

All subjects were further divided into three groups according to tertiles of FT3 level (Table 2). The liver fat content ( $\mathrm{p}$ for trend $<0.05$ ) gradually decreased with the

Table 3 Pearson correlation analysis of factors associated with FT3 and liver fat content

\begin{tabular}{|c|c|c|c|c|c|c|c|c|c|c|c|c|}
\hline \multirow[t]{3}{*}{ index } & \multicolumn{4}{|c|}{$\begin{array}{l}\text { Pearson correlation analysis } \\
(P \text {-value })\end{array}$} & \multicolumn{4}{|c|}{$\begin{array}{l}\text { Adjusted for age, gender } \\
(P \text {-value })\end{array}$} & \multicolumn{4}{|c|}{$\begin{array}{l}\text { Adjusted for age, gender, BMI } \\
(P \text {-value })\end{array}$} \\
\hline & \multicolumn{2}{|c|}{ Liver fat content } & \multicolumn{2}{|l|}{ FT3 } & \multicolumn{2}{|c|}{ Liver fat content } & \multicolumn{2}{|l|}{ FT3 } & \multicolumn{2}{|c|}{ Liver fat content } & \multicolumn{2}{|l|}{ FT3 } \\
\hline & $\mathbf{R}$ & $P$-value & $\mathbf{R}$ & $P$-value & $\mathrm{R}$ & $P$-value & $\mathbf{R}$ & $P$-value & $\mathbf{R}$ & $P$-value & $\mathbf{R}$ & $P$-value \\
\hline Age (years) & NS & & -0.315 & 0.001 & - & - & - & - & - & - & - & - \\
\hline $\mathrm{BMI}\left(\mathrm{kg} / \mathrm{m}^{2}\right)$ & 0.337 & $<0.001$ & -0.347 & $<0.001$ & 0.321 & $<0.001$ & -0.292 & 0.002 & - & - & - & - \\
\hline Waist circumference $(\mathrm{cm})$ & 0.300 & 0.006 & -0.219 & 0.049 & 0.293 & 0.009 & NS & & NS & & NS & \\
\hline $\mathrm{SBP}(\mathrm{mmHg})$ & NS & & NS & & NS & & NS & & NS & & NS & \\
\hline $\mathrm{DBP}(\mathrm{mmHg})$ & NS & & NS & & NS & & NS & & NS & & NS & \\
\hline $\mathrm{FT} 3(\mathrm{pmol} / \mathrm{L})$ & -0.328 & $<0.001$ & - & - & -0.316 & 0.001 & - & - & -0.245 & 0.009 & - & - \\
\hline $\mathrm{FT} 4(\mathrm{pmol} / \mathrm{L})$ & -0.305 & 0.001 & 0.937 & $<0.001$ & -0.291 & 0.002 & 0.930 & $<0.001$ & -0.216 & 0.021 & 0.923 & $<0.001$ \\
\hline TSH (ulU/ml) & NS & & -0.341 & $<0.001$ & NS & & -0.325 & $<0.001$ & NS & & -0.275 & 0.003 \\
\hline TG (mmol/L) & 0.284 & 0.002 & -0.239 & 0.011 & 0.274 & 0.004 & -0.191 & 0.046 & 0.209 & 0.029 & NS & \\
\hline TC $(\mathrm{mmol} / \mathrm{L})$ & 0.331 & $<0.001$ & -0.547 & $<0.001$ & 0.323 & 0.001 & -0.519 & $<0.001$ & 0.286 & 0.003 & -0.495 & $<0.001$ \\
\hline $\mathrm{LDL}(\mathrm{mmol} / \mathrm{L})$ & 0.346 & $<0.001$ & -0.543 & $<0.001$ & 0.333 & $<0.001$ & -0.513 & $<0.001$ & 0.301 & 0.001 & -0.492 & $<0.001$ \\
\hline IL6(pg/ml) & NS & & NS & & -0.194 & 0.048 & NS & & NS & & NS & \\
\hline $\mathrm{HCRP}(\mathrm{mg} / \mathrm{L})$ & NS & & NS & & -0.240 & 0.012 & NS & & -0.215 & 0.026 & NS & \\
\hline UA (umol/L) & NS & & NS & NS & NS & & NS & NS & & & & \\
\hline $\mathrm{ALT}(\mathrm{U} / \mathrm{L})$ & NS & & 0.310 & 0.001 & NS & & 0.338 & $<0.001$ & NS & & 0.336 & $<0.001$ \\
\hline $\mathrm{AST}(\mathrm{U} / \mathrm{L})$ & NS & & 0.342 & $<0.001$ & NS & & 0.374 & $<0.001$ & NS & & 0.375 & $<0.001$ \\
\hline HOMA & NS & & NS & & NS & & NS & & NS & & NS & \\
\hline
\end{tabular}


Table 4 Multiple linear regression analysis of independent factors associated with liver fat content

\begin{tabular}{|c|c|c|c|c|c|c|}
\hline \multirow{2}{*}{$\begin{array}{l}\text { Dependent } \\
\text { variable }\end{array}$} & \multicolumn{3}{|l|}{ Model $1^{\mathrm{a}}$} & \multicolumn{3}{|l|}{ Model $2^{b}$} \\
\hline & Independent variable & $\beta$ & $P$-value & Independent variable & $\beta$ & $P$-value \\
\hline \multirow[t]{2}{*}{ Liver fat content } & FT3 & -0.072 & 0.009 & FT3 & -0.059 & 0.016 \\
\hline & BMl & 0.281 & 0.007 & $\mathrm{TG}$ & 1.461 & 0.013 \\
\hline
\end{tabular}

${ }^{\mathrm{a}}$ Model $1 \mathrm{FT} 3, \mathrm{FT} 4, \mathrm{TSH}$, and BMI were included as the independent variables, adjusted with age and gender; ${ }^{\mathrm{b}} \mathrm{Model} 2 \mathrm{FT3}, \mathrm{FT4}, \mathrm{TSH}, \mathrm{TG}, \mathrm{CHOL}, \mathrm{LDL}$, systolic blood pressure, diastolic blood pressure, UA, IL-6, and HCRP were included as the independent variables, adjusted with age, gender and BMI

increasing of FT3. The liver fat content in the 3rd tertile $(4.01 \pm 2.43 \%)$ was significantly lower than that in 1 st tertile $(6.75 \pm 3.45 \%)$ and 2 nd tertile $(6.14 \pm 4.34 \%)$; The prevalence of NAFLD also showed a gradual downward trend ( $\mathrm{p}$ for trend $<0.05$ ). The prevalence of NAFLD in the 3rd tertile $(1 / 38)$ was significantly lower than that in the 1 st tertile $(10 / 29)$, but there was no statistical difference between the 3rd tertile and 2nd tertile (3/36). (Fig. 1 a-b). In addition, the levels of BMI, TG, TC, and LDL-c gradually decreased, and the levels of ALT and AST gradually increased with the increasing of FT3 ( $\mathrm{p}$ for trend $<0.01)$. There were no significant differences in gender, Wc, blood pressure level, FBG, fasting insulin, UA, IL-6, HCRP and HOMA-IR among the three groups $(p>0.05)$. After adjustment for age, gender, and BMI, the association of liver fat content still reached the statistical significance $(p<0.01)$.

Significant correlation was found between FT3 and liver fat content $(R=-0.328, P<0.01)$, the correlation was significant after adjusting for age, gender and BMI $(\mathrm{R}=-0.245, \mathrm{P}<0.01$ ) (Fig. 1c, Table 3). Pearson correlation analysis showed that FT3 was negatively correlated with BMI, Wc, TG, TC and LDL, and positively correlated with ALT and AST (Table 3). The association of FT3 with TC, LDL, ALT and AST were still significant after adjusting for age, gender and BMI $(P<0.01)$.

As shown in Table 4, multiple linear regression analysis was used to analyze the independent risk factors associated with liver fat content in hyperthyroidism patients. Model 1 included FT3, FT4, TSH, and BMI, and adjusted for age and gender. The results showed that FT3 $(p<0.01)$ and BMI $(p<0.01)$ were independently correlated with the liver fat content. The full model 2 further included the FT3, FT4, TSH, TG, CHOL, LDL, systolic blood pressure, diastolic blood pressure, UA, IL - 6, HCRP as the independent variables, and adjusted for age, gender and BMI. The results showed that FT3 $(p<$
$0.05)$ and TG $(p<0.05)$ were independently correlated with liver fat content.

In the binary logistic regression analysis (Table 5), after adjustment with age and gender, FT3, FT4, TSH, and BMI tertiles were used and independent variables, and the results showed FT3 (OR 0.297, 95\% CI.0.106 0.832), and BMI (OR 4.585, 95\% CI.1.488 14.128) was independently associated with NAFLD. In full Model 2, FT4, TSH, TG, CHOL, LDL, Systolic blood pressure, diastolic blood pressure, UA, IL6, and HCRP tertiles were included, adjusted variable of age, gender and BMI. The results showed FT3 (OR 0.267, 95\% CI.0.087 0.817 ) were still independently associated with NAFLD.

\section{Discussion}

The present study reported that the prevalence of NAFL D was $11.97 \%$ in 117 clinical hyperthyroidism patients. Liver fat content was closely related to the FT3 levels in this population, and this association was independent of metabolic components and inflammatory factors.

The prevalence of NAFLD is $27.4-33.1 \%$ in euthyroidism population, and $35.7-36.3 \%$ in hypothyroidism population [1-3]. However, there are extremely limited reports on the prevalence of NAFLD in hyperthyroid population. From Rotterdam Study, the prevalence of NAFLD was $21.5 \%$ in hyperthyroidism subjects, and a decreasing trend of NAFLD prevalence was found in different thyroid status from hypothyroidism, euthyroidism to hyperthyroidism [20]. NAFLD risk decreased gradually from hypothyroidism to hyperthyroidism. However, 114 subjects were in subclinical status, there were only 7 clinical hyperthyroidism cases were included in Rotterdam Study. Our data showed that the prevalence of NAFLD $11.95 \%$ in clinical hyperthyroidism subjects, which was lower than subclinical hyperthyroidism and other thyroid status population. To be consistent of our

Table 5 Binary logistic regression analysis of risk factors for NAFLD

\begin{tabular}{lllll}
\hline Binary logistic regression analysis & $\begin{array}{l}\text { Independent } \\
\text { variable }\end{array}$ & P-value & OR & 95\% C.I. \\
\hline Model1 $^{\mathrm{a}}$ & FT3 & 0.021 & 0.297 & $0.106-0.832$ \\
& BMl & 0.008 & 4.585 & $1.488-14.128$ \\
Model2 $^{\mathrm{b}}$ & FT3 & 0.021 & 0.267 & $0.087-0.817$ \\
\hline
\end{tabular}

a Model 1 tertiles of FT3, FT4, TSH, and BMI were included as the independent variables, adjusted with age and gender; ${ }^{\text {b }}$ Model 2 tertiles of FT3, FT4, TSH, TG, $\mathrm{CHOL}$, LDL, systolic blood pressure, diastolic blood pressure, UA, IL-6, and HCRP were included as the independent variables, adjusted with age, gender and BMI 
findings, a case also reported that hyperthyroidism improved the pathological condition of NASH [21].

The results of the present study indicated a negative linear association between FT3 levels and NAFLD in this specific hyperthyroidism population. Several study demonstrated the association of thyroid hormone and NAFLD in different thyroid status population. The serum thyroxin (TT4) concentration in subjects with hepatic steatosis was reduced in subclinical and clinical hypothyroidism subjects [10]. Subclinical hypothyroidism and low-normal thyroid function are associated with NASH and fibrosis according to the TSH levels [22].From lifeline cohort study, higher FT3is associated with NAFLD in euthyroid subjects [23].Higher FT4 levels were associated with a decreased risk of NAFLD, and higher thyroid-stimulating hormone levels were associated with increased risk of having clinically relevant fibrosis in NAFLD in Rotterdam study [20]. Our study demonstrated that FT3 level was independently associated with decreased liver fat content in the hyperthyroidism population. TSH levels were significantly suppressed in hyperthyroidism subjects, which can not accurately reflect the thyroid function. In addition, FT3 activity is much higher than FT4 [24, 25], so it is more authentic to regard FT3 level as an indicator of thyroid function in patients with hyperthyroidism. Therefore, in hyper-metabolic hyperthyroid population, FT3 is independently associated with liver fat content, while in hypothyroid or euthyroid population, TSH or FT4 and NAFLD are closely related.

The mechanisms about the effect of thyroid hormone levels on liver fat content and NAFLD remain unclear. Study of rodent models have demonstrated that thyroid receptor $\beta$ agonist MB07811 can reduce hepatic steatosis [12]. Thyroid hormone induces intrahepatic lipolysis via activation of autophagy [26]. Previous studies on the hypothyroidism patients indicated that lower thyroid hormone caused insulin resistance, metabolic disorders, and NAFLD [27, 28]. Our results indicated that thyroid hormone further reduced liver fat content in the condition of hyperthyroidism. Thyroid hormone may promote body fat consumption, and reduce body weight, it may also directly impact on the liver, accelerating intrahepatic fat clearance, this process was independent from metabolic factors and inflammatory factors.

Previous studies have shown hypothyroidism is related to NAFLD, and the level of thyroid hormone in hypothyroidism or euthyroidism population is closely related to liver fat content. Our study also showed that the prevalence of NAFLD in hyperthyroid populations is $11.97 \%$, which was lower than the $27.4-33.1 \%$ in euthyroidism population as indicated in previous studies. Our study further expanded the study population and explored the effect of pathologically elevated thyroid hormones on NAFLD in patients with hyperthyroidism. The results showed that FT3 in patients with hyperthyroidism was significantly negatively correlated with liver fat content and was independent from other wellestablished NAFLD-related risks factors including BMI, TG, CRP, IL-6, etc. These findings expanded the significant association of thyroid hormone and NAFLD in hypothyroidism and euthyroidism population, elevated thyroid hormone levels can reduce liver fat content regardless of the thyroid functional status of the population.

There are still some limitations in this study: 1) Lack of follow-up data in this cross-sectional study; 2) The sample size was not estimated before the study, and the sample size was small. Due to the characteristics of the disease, the gender distribution of the included cases was unequal; 3) The study is limited to clinic-based setting which may be potentially responsible for bias in the results obtained; 4) Ler biopsy or liver magnetic resonance spectroscopy (MRS) were not used to accurately detect liver fat content. The results above still need to be further confirmed by improving the experimental design and following up closely.

\section{Conclusion}

In conclusion, The present study reported that the prevalence of NAFLD was $11.97 \%$ in 117 clinical hyperthyroidism patients. In addition, the prevalence and liver fat content significantly decrease with the elevation of FT3 levels in this population. These results may provide new evidence in the role of thyroid hormone on the regulation of liver fat content and NAFLD.

\section{Abbreviations \\ NAFLD: Non-alcoholic fatty liver disease; FT3: Free triiodothyronine; FT4: Free thyroxine; NASFL: Non-alcoholic simple fatty liver; NASH: Nonalcoholic steatohepatitis; FFA: Free fatty acids; TSH: Thyroid stimulating hormone; Wc: Waist circumference; BMI: Body mass index; FBG: Fasting blood glucose; TC: Total cholesterol; TG: Triglyceride; HDL-C: High-density lipoprotein cholesterol; LDL-C: Low-density lipoprotein cholesterol; ALT: Alanine aminotransferase; AST: Aspartate aminotransferase; UA: Uric acid; \\ TRAb: Thyrotrophin receptor antibody; f-INS: Fasting plasma insulin; HCRP: Hyper-sensitive C-reaction protein; HOMA-IR: Insulin resistance index; ROI: Region of interest}

\section{Acknowledgments}

The authors are grateful to all of the subjects who participated in this study.

\section{Disclosure summary}

I certify that neither I nor my co-authors have a conflict of interest as described above that is relevant to the subject matter or materials included in this work.

\section{Authors' contributions}

BW and XL participated in the design of the study, performed the statistical analysis and drafted the manuscript. $X G$ and $X L$ participated in the design of the study. BX, MH and JX participated in the data collection. XL and XG conceived of the study. All authors read and approved the final manuscript.

\section{Funding}

This work was supported by the National Science Foundation of China (81770770, 2017; 81970695, 2017). 


\section{Availability of data and materials}

The data that support the findings of this study are available from the corresponding author upon reasonable request.

\section{Ethics approval and consent to participate}

Written, informed consent was obtained from all of the participants, and the study was approved by the ethics committee of Zhongshan Hospital, Fudan University, China.

\section{Consent for publication}

Not Applicable.

\section{Competing interests}

I certify that neither I nor my co-authors have a conflict of interest as described above that is relevant to the subject matter or materials included in this work.

\section{Author details}

'Present address: The Department of Endocrinology, Zhongshan hospital, Fudan University, NO. 180 Fenglin Road, Shanghai 200032, China.

${ }^{2}$ Department of Endocrinology and Metabolism, Jinjiang Municipal Hospital, Jinjiang 362200, China.

Received: 7 August 2020 Accepted: 9 February 2021

\section{Published online: 18 February 2021}

\section{References}

1. Frith J, Day CP, Henderson E, Burt AD, Newton JL. Non-alcoholic fatty liver disease in older people. Gerontology. 2009;55(6):607-13.

2. Zelber-Sagi S, Nitzan-Kaluski D, Halpern Z, Oren R. Prevalence of primary non-alcoholic fatty liver disease in a population-based study and its association with biochemical and anthropometric measures. Liver Int. 2006; 26(7):856-63.

3. Xu C, Xu L, Yu C, Miao M, Li Y. Association between thyroid function and nonalcoholic fatty liver disease in euthyroid elderly Chinese. Clin Endocrinol (Oxf). 2011;75(2):240-6.

4. Petta S, Craxi A. Hepatocellular carcinoma and non-alcoholic fatty liver disease: from a clinical to a molecular association. Curr Pharm Des. 2010; 16(6):741-52.

5. Eslam M, Valenti L, Romeo S. Genetics and epigenetics of NAFLD and NASH: clinical impact. J Hepatol. 2018;68:268-79.

6. Day CP, James OF. Steatohepatitis: a tale of two "hits"? Gastroenterology 1998;114(4):842-5. https://doi.org/10.1016/s0016-5085(98)70599-2.

7. Duntas LH, Brenta G. The effect of thyroid disorders on lipid levels and metabolism. Med Clin North Am. 2012;96(2):269-81.

8. Maratou E, Hadjidakis DJ, Kollias A, et al. Studies of insulin resistance in patients with clinical and subclinical hypothyroidism. Eur J Endocrinol. 2009; 160(5):785-90

9. Rochon C, Tauveron I, Dejax C, et al. Response of glucose disposal to hyperinsulinaemia in human hypothyroidism and hyperthyroidism. Clin Sci (Lond). 2003;104(1):7-15.

10. Ludwig U, Holzner D, Denzer $C$, et al. Subclinical and clinical hypothyroidism and non-alcoholic fatty liver disease: a cross-sectional study of a random population sample aged 18 to 65 years. BMC Endocr Disord. 2015;15:41.

11. Gnocchi D, Massimi M, Alisi A, Incerpi S, Bruscalupi G. Effect of fructose and 3,5-diiodothyronine (3,5-T(2)) on lipid accumulation and insulin signalling in non-alcoholic fatty liver disease (NAFLD)-like rat primary hepatocytes. Horm Metab Res. 2014;46(5):333-40

12. Cable EE, Finn PD, Stebbins JW, et al. Reduction of hepatic steatosis in rats and mice after treatment with a liver-targeted thyroid hormone receptor agonist. Hepatology. 2009;49(2):407-17.

13. George J, Liddle C. Nonalcoholic fatty liver disease: pathogenesis and potential for nuclear receptors as therapeutic targets. Mol Pharm. 2008;5(1): 49-59.

14. Arrese M. Burning hepatic fat: therapeutic potential for liver-specific thyromimetics in the treatment of nonalcoholic fatty liver disease. Hepatology. 2009:49(2):348-51.

15. Andryskowski G, Owczarek T. The evaluation of selected oxidative stress parameters in patients with hyperthyroidism. Pol Arch Med Wewn. 2007 117(7):285-9.
16. Xia MF, Yan HM, He WY, et al. Standardized ultrasound hepatic/renal ratio and hepatic attenuation rate to quantify liver fat content: an improvement method. Obesity (Silver Spring). 2012;20(2):444-52.

17. Torun E, Özgen IT, Gökçe S, et al. Thyroid hormone levels in obese children and adolescents with non-alcoholic fatty liver disease. J Clin Res Pediatr Endocrinol. 2014;6(1):34-9.

18. Carulli L, Ballestri S, Lonardo A, et al. Is nonalcoholic steatohepatitis associated with a high though-normal thyroid stimulating hormone level and lower cholesterol levels? Intern Emerg Med. 2013;8(4):297-305.

19. Dullaart RPF, Van den Berg EH, Van der Klauw MM, et al. Low normal thyroid function attenuates serum alanine aminotransferase elevations in the context of metabolic syndrome and insulin resistance in white people. Clin Biochem. 2014;47(12):1028-32.

20. Bano A, Chaker L, Plompen EP, et al. Thyroid function and the risk of nonalcoholic fatty liver disease: the Rotterdam study. J Clin Endocrinol Metab. 2016;101(8):3204-11.

21. Miyake T, Matsuura B, Furukawa S, et al. Hyperthyroidism improves the pathological condition of nonalcoholic Steatohepatitis: a case of nonalcoholic Steatohepatitis with Graves' disease. Intern Med. 2016;55(15): 2019-23.

22. Kim D, Kim W, Joo SK, Bae JM, Kim JH, Ahmed A. Subclinical hypothyroidism and low-Normal thyroid function are associated with nonalcoholic Steatohepatitis and fibrosis. Clin Gastroenterol Hepatol. 2018; 16(1):123-31 e121.

23. van den Berg EH, van Tienhoven-Wind $\amalg$, Amini M, et al. Higher free triiodothyronine is associated with non-alcoholic fatty liver disease in euthyroid subjects: the lifelines cohort study. Metabolism. 2017;67:62-71.

24. Ingbar SH, Braverman LE. Active form of the thyroid hormone. Annu Rev Med. 1975;26:443-9.

25. Lazar MA. Thyroid hormone receptors: multiple forms, multiple possibilities. Endocr Rev. 1993;14(2):184-93.

26. Sinha RA, You SH, Zhou J, et al. Thyroid hormone stimulates hepatic lipid catabolism via activation of autophagy. J Clin Invest. 2012;122(7):2428-38.

27. Khan SH, Fazal N, ljaz A, et al. Insulin resistance and glucose levels in subjects with subclinical hypothyroidism. J Coll Physicians Surg Pak. 2017; 27(6):329-33.

28. Nada AM. Effect of treatment of overt hypothyroidism on insulin resistance. World J Diabetes. 2013;4(4):157-61.

\section{Publisher's Note}

Springer Nature remains neutral with regard to jurisdictional claims in published maps and institutional affiliations.

Ready to submit your research? Choose BMC and benefit from:

- fast, convenient online submission

- thorough peer review by experienced researchers in your field

- rapid publication on acceptance

- support for research data, including large and complex data types

- gold Open Access which fosters wider collaboration and increased citations

- maximum visibility for your research: over $100 \mathrm{M}$ website views per year

At $\mathrm{BMC}$, research is always in progress.

Learn more biomedcentral.com/submissions 